\title{
Stages in the second reaction of pre-mRNA splicing: the final step is ATP independent
}

\author{
David S. Horowitz ${ }^{1}$ and John Abelson \\ Division of Biology 147-75, California Institute of Technology, Pasadena, California 91125 USA
}

\begin{abstract}
We have analyzed pre-mRNA splicing in yeast extracts immunodepleted of the PRP18 protein. We find that while the first step of splicing (cleavage at the $5^{\prime}$ splice site, and generation of the exon 1 and lariat intermediates) is unaffected by the absence of PRP18, the second step of splicing (excision of the lariat intron and formation of mRNA) is substantially slower in the absence of PRP18. The splicing intermediates that are formed in the absence of PRP18 can be rapidly chased into products by the addition of purified PRP18 protein. This chasing is not dependent on ATP, implying that ATP is not required during the second cleavage-and-ligation reaction. This result suggests that there are ordered stages within the second step of splicing and that PRP18 acts late in the second step, perhaps during the catalytic step. The ATP independence also supports the idea that this reaction proceeds by a transesterification mechanism.
\end{abstract}

[Key Words: Pre-mRNA splicing; U5 snRNP; PRP18; Saccharomyces cerevisiae]

Received September 25, 1992; revised version accepted November 30, 1992.

The splicing of pre-mRNA takes place on a large ribonucleoprotein particle called the spliceosome, which consists of five small nuclear RNAs (snRNAs), U1, U2, U4, $\mathrm{U} 5$, and U6, and a large number of proteins (for review, see Green 1991; Guthrie 1991; Ruby and Abelson 1991). Splicing of pre-mRNA is a two-step process. In the first step, the pre-mRNA is cleaved at the $5^{\prime}$ splice site, releasing the first exon; concomitantly, the $5^{\prime}$ phosphoryl group at the end of the intron is ligated to the 2 ' hydroxyl of an internal adenosine, yielding a branched RNA termed a lariat. In the second step, cleavage at the $3^{\prime}$ splice site is accompanied by ligation of the two exons, yielding the product mRNA and releasing the intron as a lariat. These two steps are formally the same as those that occur in the self-splicing of group II introns (Peebles et al. 1986; van der Veen et al. 1986). From the analogy with group II self-splicing, each of the two steps of premRNA splicing has been hypothesized to be a transesterification reaction, in which the number of phosphodiester bonds is conserved (Cech 1986; Jacquier 1990). The analogy also suggests that RNA may play an important role in the catalysis of the splicing reaction. In contrast to self-splicing, ATP is required for the splicing of premRNA. It has been hypothesized that ATP hydrolysis is involved in proofreading or in conformational changes within the spliceosome. In the splicing of pre-tRNA, ATP hydrolysis is coupled to the ligation of the two ex-

${ }^{1}$ Present address: Cold Spring Harbor Laboratory, Cold Spring Harbor, New York 11724 USA ons, but it has not been determined whether ATP might have a similar role in pre-mRNA splicing.

In this paper we focus on the second step of splicing in Saccharomyces cerevisiae. At least four proteins, called PRP16, PRP17, PRP18 (for pre-mRNA processing), and SLU7 (for synergistically lethal with U 5 ), appear to be required for the second step. PRP16 was found as a second site suppressor of a mutation in the invariant TACTAAC sequence located at the branchpoint in all S. cerevisiae introns (Couto et al. 1987). PRP16 is an RNAdependent ATPase (Burgess et al. 1990; Schwer and Guthrie 1991), which appears to mediate a conformational change in the spliceosome preceding the second reaction of splicing (Schwer and Guthrie 1992). PRP17 was found in a screen for yeast strains that were temperature sensitive for splicing (Vijayraghavan et al. 1989) and was found again as a synthetic lethal with U5 (SLU4) (Frank et al. 1992), but has not yet been further characterized. PRP18, the focus of this study, was found in the same screen that yielded PRP17 (Vijayraghavan et al. 1989). Initial work showed that PRP18 was involved in the second step of splicing /Vijayraghavan and Abelson 1990), and we have recently found that PRP18 is associated with the U5 snRNP (D. Horowitz and J. Abelson, in prep.). SLU7 is a synthetic lethal with some mutations in the U5 snRNA (Frank et al. 1992) and appears to be involved in the recognition of the 3' splice site (Frank and Guthrie 1992).

Two snRNAs, U2 and U6, have been shown to be directly involved in the second step of splicing. Fabrizio and Abelson (1990) analyzed the effects of a large number 
of mutations in the U6 snRNA in vitro; McPheeters and Abelson (1992) carried out a similar analysis of U2. In both cases, a small number of the mutations analyzed resulted in the accumulation of intermediates in the splicing reaction, showing that both snRNAs are important for the second step. A role for the U1 and U5 snRNAs in $3^{\prime}$ splice site recognition has been inferred from genetic experiments. Reich et al. (1992) have suggested that U1 base-pairs to the conserved AG at the $3^{\prime}$ splice site, whereas Newman and Norman (1992) have found evidence that U5 base-pairs to the first two nucleotides in exon 2. Whether these base-pairing interactions are important during the actual splicing reaction is unknown.

In the present work, we show that PRP18 is involved only in the second step of splicing. In splicing reactions carried out in vitro, intermediates accumulate in the absence of PRP18. These intermediates can be chased to products by the addition of PRP18. We find that this chase does not require ATP, providing strong support for a transesterification mechanism for the second step of pre-mRNA splicing, and suggesting that PRP18 acts during the second transesterification reaction.

\section{Results}

\section{Immunodepletion of PRP18}

Antibodies against recombinant PRP18 were raised in rabbits (D. Horowitz and J. Abelson, in prep.). Immunodepletion of a yeast extract was carried out by incubating extracts with protein A-bound $\alpha$ PRP18. Some antibody was released from the resin during this incubation, and most of the released antibody was removed by a subsequent incubation with protein A-Sepharose. A Western blot of immunodepleted extract, probed with $\alpha$ PRP18, is shown in Figure 1. PRP proteins are typically difficult to detect (Jackson et al. 1988; Banroques and Abelson 1989; Petersen-Bjørn et al. 1989); so a high background in the blot is not unexpected. Quantitation of the blot pictured showed that $>95 \%$ of the PRP1 18 had been removed. A faint band seen at the position of PRP18 in the $\alpha$ PRP18depleted extract is also seen with similar intensity in extract from the strain DH120R, in which the PRP18 gene has been disrupted. None of the other proteins seen by blotting could be immunoprecipitated by $\alpha$ PRP 18 (data not shown).

\section{Kinetics of splicing}

Initial work with extracts from prp18 temperature-sensitive yeast showed that PRP18 was involved in the second step of splicing (Vijayraghavan et al. 1989; Vijayraghavan and Abelson 1990). We also found this result by $\alpha$ PRP18 inhibition of splicing (D. Horowitz and J. Abelson, in prep.l, but neither of these studies showed whether PRP18 might also be involved in the first step of splicing or whether PRP18 was absolutely required for the second step. To answer these questions, we have analyzed the kinetics of splicing in wild-type extracts depleted of PRP18. We used standard splicing conditions

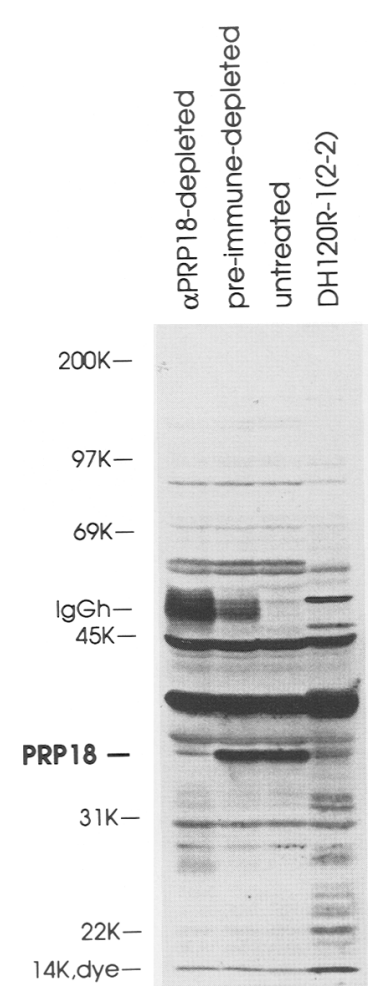

Figure 1. Western blot of a PRP18-depleted extract. Shown are $15 \mu \mathrm{g}$ of total protein from an $\alpha$ PRP18-depleted extract, from a preimmune antibody-depleted extract, from an untreated extract, and from an extract of the strain DH120R-1(2-2), in which the PRP18 gene had been disrupted. The band corresponding to PRP18 is indicated; the assignment was based on the mobility of the purified protein and its absence in the PRP18-disrupted strain (D. Horowitz and J. Abelson, in prep.). The band from residual IgG heavy chain is also indicated. The first three lanes show splicing extracts made from the strain $\mathrm{CBO} 18$, the last lane shows a Zymolyase-SDS extract of DH120R-1(2-2). SDS extracts gave higher backgrounds in our blots. The blot was probed with affinity-purified $\alpha$ PRP18.

at $23^{\circ} \mathrm{C}$ (Lin et al. 1985). A gel of a time course of splicing in preimmune antibody-depleted and $\alpha$ PRP18-depleted extracts is shown in Figure 2A. Quantitative analyses of the gel are plotted in Figure 2B-D. In Figure 2B the kinetics of disappearance of pre-mRNA in the two extracts are compared; in Figure 2, C and D, the kinetics of formation of $2 / 3$ lariat, exon 1 , and mRNA are shown for each of the two extracts. The kinetics of splicing in the preimmune antibody-depleted extract and an untreated extract were essentially identical (data not shown). It is apparent from the gel (Fig. 2A) that the second step of splicing is inhibited in the PRP18-depleted extract. The $2 / 3$ lariat and exon 1 intermediates accumulate; however, the second step of splicing is not completely inhibited, and mRNA is produced slowly. There are two interpretations of this result: Either PRP18 has not been completely depleted or PRP18 is not absolutely required for splicing. We favor the latter interpretation (see Discussion; D. Horowitz and J. Abelson, in prep..) Two as- 


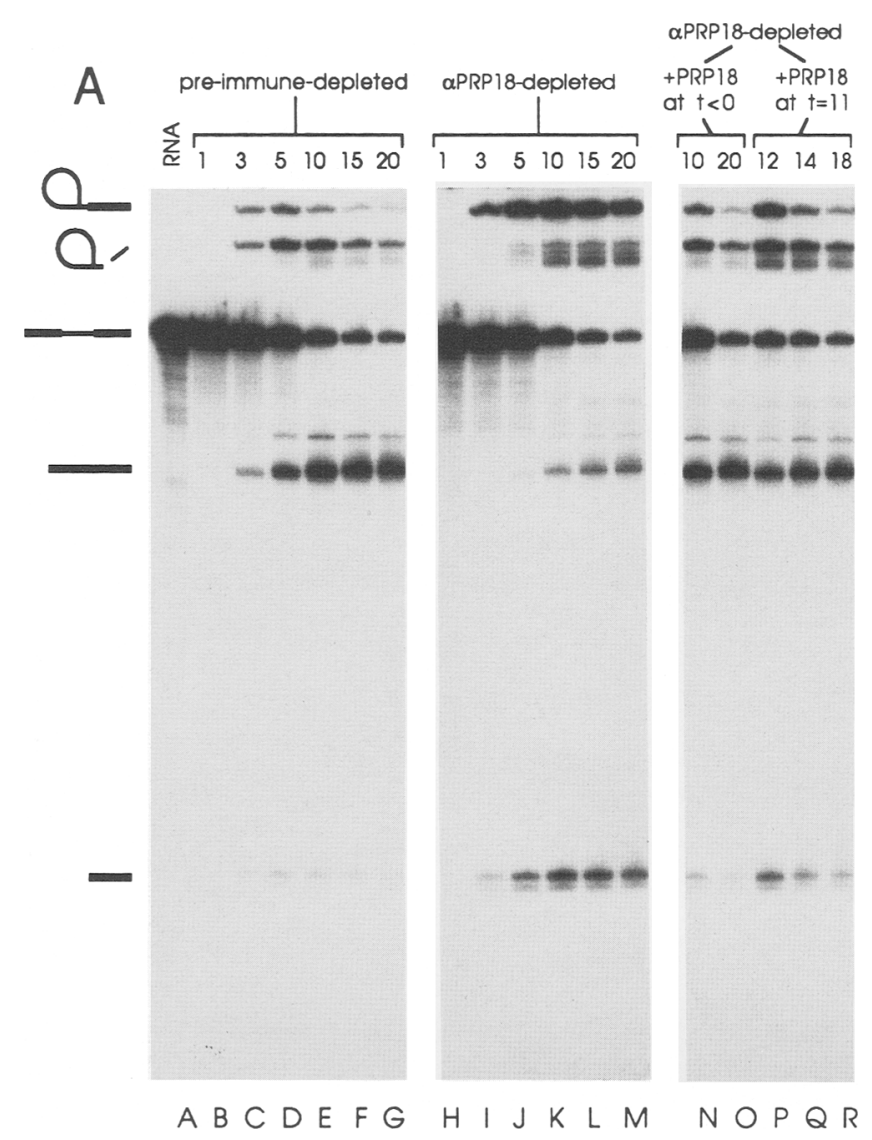

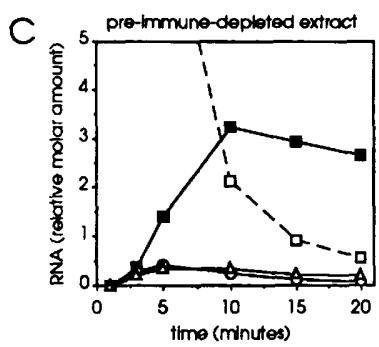
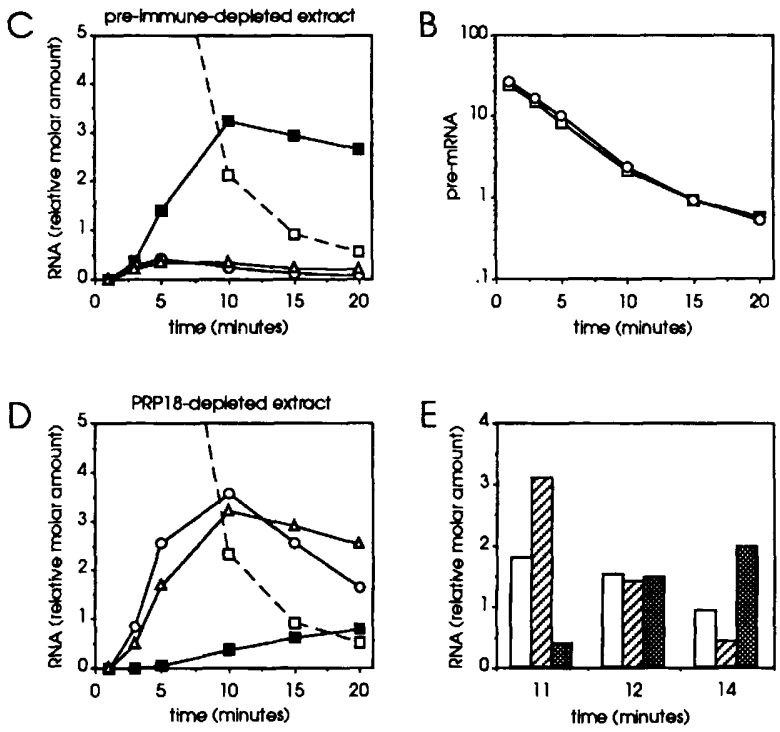

Figure 2. Kinetics of splicing and chasing of intermediates to products by PRP18. (A) A gel showing the time courses of splicing in preimmune antibody-depleted (lanes $B-G$ ) and $\alpha$ PRP18-depleted (lanes $H-M$ ) extracts. The time points are indicated in minutes at the top of each lane. Lane $A$ shows pre-mRNA only. Two other results are also presented. The first is a splicing reaction with an $\alpha$ PRP18-depleted extract to which PRP18 had been added before the start of the splicing reaction (lanes $N, O$ ). The second is a chase of intermediates to products by the addition of PRP18; for this experiment, an aliquot of the splicing reaction using $\alpha$ PRP18-depleted extract (shown in lanes $H-M$ ) was removed at $11 \mathrm{~min}$, PRP18 was added to this aliquot, and splicing
en rounded to the nearest minute. The positions of the $2 / 3$ lariat, was assayed at the indicated times (lanes $P-R)$. All times have been rounded to the nearest minute. The positions of the $2 / 3$ lariat,
intron, pre-mRNA, mRNA, and exon 1 are indicated symbolically. A single exposure of one gel is shown; the lanes have been rearranged for clarity. $(B)$ A comparison of the rates of disappearance of pre-mRNA in the splicing reactions displayed in $A$. ( $\square$ ) Preimmune antibody-depleted extract; $(O) \alpha P R P 18$-depleted extract. $(C, D)$ Graphs of the kinetics of splicing in preimmune antibodydepleted $(C)$ and $\alpha$ PRP18-depleted $(D)$ extracts. Pre-mRNA $(\square), 2 / 3$ lariat $(O)$, exon $1(\triangle)$, and mRNA $(\square)$ are shown. $(E)$ Bar graph showing the chasing of intermediates to products from $A$. PRP18 was added at $11 \mathrm{~min}$. The amounts of mRNA (open), $2 / 3$ lariat (hatched), and mRNA (stippled) are shown. Values for $11 \mathrm{~min}$ were interpolated from $D$. (The interpolated values are $<15 \%$ different from those at $10 \mathrm{~min}$; the conclusions discussed in the text do not depend on the precision of the interpolations.) All values graphed in $B-E$ were obtained from PhosphorImager quantitation of the gel shown in $A$; all RNAs are in relative molar amounts (arbitrary units), obtained by dividing the measured quantity from the PhosphorImager analysis (in arbitrary units) by the molecular weight of the RNA species. The vertical scales in $B-E$ are in the same units.

pects of the analysis show that the first step of splicing is unaffected by the depletion of PRP18. The rates of disappearance of pre-mRNA in the two extracts are identical; because this process may be dominated by degradation of the pre-mRNA, it is not conclusive evidence that the first step is unaffected (Fig. 2B). More convincingly, the amounts of pre-mRNA that have undergone the first step of splicing (given by the sum of the molar amounts of $2 / 3$ lariat and mRNA in Fig. $2 C, D$ ) are essentially the same in both extracts.

The apparent yield of products in our splicing reactions was $15-20 \%$, although $98 \%$ of the pre-mRNA is consumed during the reaction. Much of the RNA added to the extract has been degraded, and the stabilities of the various RNA species are different. Lariat intron is clearly less stable than mRNA [in Fig. 2A, six times more mRNA than lariat intron RNA (by molar amount) was present in the preimmune antibody-depleted extract after $20 \mathrm{~min}]$, and pre-mRNA also appears to be relatively unstable (see Fig. $2 \mathrm{C}, \mathrm{D}$ ). Exon 1 is more stable than $2 / 3$ lariat, perhaps owing to the difference in sizes. The variable stabilities of the RNAs and the complexity of the splicing reaction precluded any attempt to derive kinetic rate constants for the full splicing reaction. However, with some approximations, we can estimate a rate constant for the second step of splicing, as detailed in Materials and methods. We find that the second step is 80-fold slower in the PRP18-depleted extract than in the wild-type extract.

\section{Activity of PRP18 protein}

To determine whether purified PRP18 protein was active, we assayed splicing in a PRP18-depleted extract to 
which purified recombinant PRP18 had been added. PRP18 was added to the PRP18-depleted extract immediately before the addition of the splicing cocktail. Essentially wild-type splicing was seen (Fig. 2A, lanes $\mathrm{N}, \mathrm{O}$. Comparison of the splicing in the preimmune-depleted extract (Fig. 2A, lanes E,G), the $\alpha$ PRP18-depleted extract (Fig. 2A, lanes K,M), and the PRP18-returned extract (Fig. 2A, lanes $\mathrm{N}, \mathrm{O}$ ) shows that normal splicing activity had been restored. This result demonstrates both that the purified PRP18 protein is active and that the PRP18-depleted extract has been specifically depleted of PRP18. About 40 times as much PRP18 as is present in a wild-type extract was added in this experiment (and in subsequent chasing experiments) to ensure rapid and complete reconstitution of activity. We have not determined the specific activity of our PRP18.

\section{Chasing of intermediates to products by PRP18}

Figure $2 \mathrm{~A}$ shows the accumulation of intermediates in a PRP18-depleted extract; we wished to determine whether these intermediates could be chased to products by the addition of PRP18 protein. Splicing was carried out in a PRP18-depleted extract for $11 \mathrm{~min}$ for optimal formation of intermediates (Fig. 2). A portion of the reaction shown in Figure $2 \mathrm{~A}$ (lanes $\mathrm{H}-\mathrm{K}$ ) was removed after $11 \mathrm{~min}$ for the chasing experiment. PRP18 was added, and aliquots were periodically removed for assay, as shown in Figure 2A (lanes P-R). Rapid chasing of the $2 / 3$ lariat and exon 1 intermediates to mRNA and lariat intron was seen (Fig. 2A, cf. lanes $\mathrm{K}$ and $\mathrm{P}$ ); the results are shown graphically in Figure 2E. [Although lane K shows the splicing reaction $1 \mathrm{~min}$ before the chase was initiated, it is a suitable reference lane, as the amounts of the RNA species were changing slowly (Fig. 2D).] About half of each intermediate was converted to product within 1 min, although the apparent yield of mRNA from $2 / 3$ lariat is only $\sim 60 \%$, presumably owing to the instability of the RNA. This chase confirms the idea that the lariat $2 / 3$ and exon 1 are intermediates in the splicing pathway. Comparison of the amounts of RNA (Fig. 2E) at the beginning of the chase at $11 \mathrm{~min}$ (Fig. 2A, lane $\mathrm{K}$ ) and the first time point at $12 \mathrm{~min}$ (Fig. $2 \mathrm{~A}$, lane $\mathrm{P}$ ) shows that the changes in the amounts of RNA are $\Delta$ pre-mRNA $=-0.3, \Delta 2 / 3$ lariat $=-1.7, \Delta$ exon $1=-1.0$, and $\Delta$ mRNA $=+1.1$ (relative molar amounts). The amount of mRNA produced is fourfold larger than the amount of pre-mRNA consumed during the chase; hence, the mRNA must have been produced from the $2 / 3$ lariat and exon 1.

To determine whether the chasing of intermediates to products required ATP, we first developed a method for depleting ATP in yeast splicing reaction mixtures. The initial concentration of ATP in splicing reactions was 2 $\mathrm{mM}_{\text {; }}$ after $10 \mathrm{~min}$, at which time we wanted to remove the ATP, its concentration had fallen to $1 \mathrm{~mm}$. We initially used hexokinase and glucose to deplete ATP (Black and Pinto 1989) but found that the hexokinase was superfluous; addition of $2 \mathrm{~mm}$ glucose resulted in destruc- tion of the remaining ATP. Depletion of ATP was monitored with tracer $\left[\alpha{ }^{-32} \mathrm{P}\right] \mathrm{ATP}$, which was analyzed by thin-layer chromatography (TLC) in $1.2 \mathrm{MLiCl}$ (Randerath and Randerath 1964). A typical result is shown in Figure 3. ATP was destroyed rapidly $(<3 \mathrm{~min})$; ATP was not detected either by long exposure or with the PhosphorImager. The TLC results showed that the concentration of ATP remaining after the depletion was $<5 \mu \mathrm{M}$. We have also measured the concentration of ATP using the luciferase-luciferin bioluminescence assay, which gave an ATP concentration of 2-3 $\mu \mathrm{M}$, consistent with the TLC results. We are uncertain what the processes leading to the depletion of ATP are; some AMP, but very little ADP, was seen after the ATP was depleted. Endogenous hexokinase and nucleoside monophosphate kinase may be reponsible for these results. Similar experiments to track the other NTPs, as well as dATP, were done (Fig. 3). In these experiments, $\left[\alpha^{32}\right.$ P]NTP (or $\left.\left[\alpha-{ }^{32} \mathrm{P}\right] \mathrm{dATP}\right)$ was substituted for $\left[\alpha^{-32} \mathrm{P}\right] \mathrm{ATP}$. Following incubation under splicing conditions, the NTP was analyzed by TLC. In all cases, substantial depletion of the NTP was seen. The concentration of CTP was reduced by $>400$-fold, GTP by 40 -fold, UTP by $>50$-fold, and dATP by 75 -fold. The total NTP concentration was mea-

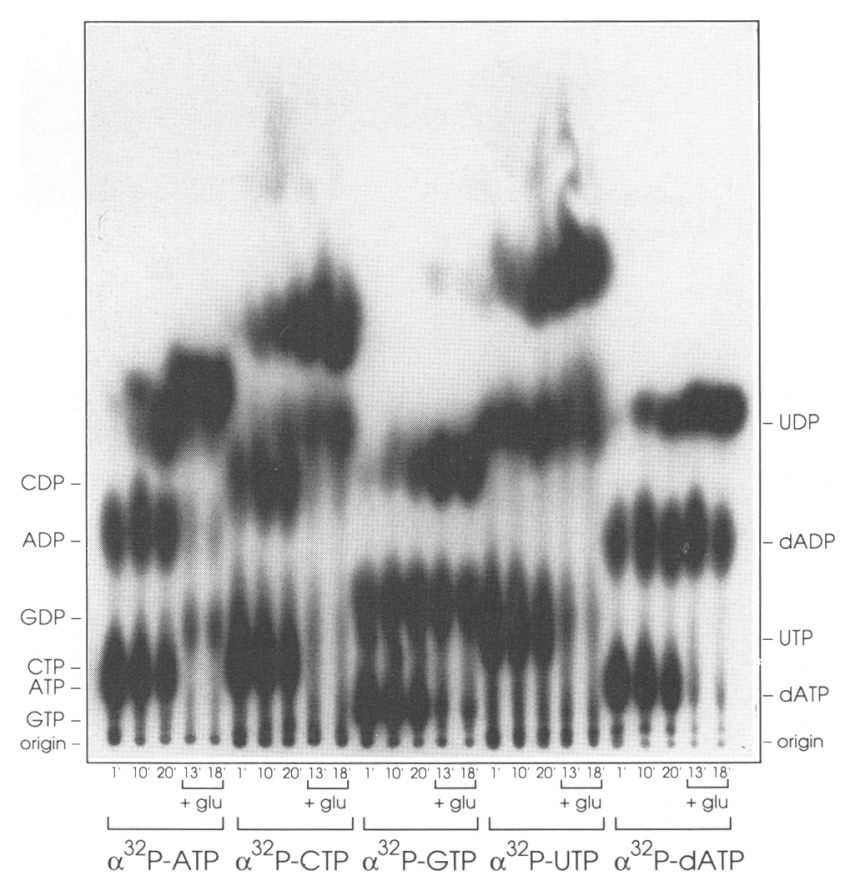

Figure 3. Thin-layer chromatograph showing the fates of the four NTPs and dATP in a splicing reaction and following glucose-caused depletion. For each of the five reactions, the $\alpha^{-32} \mathrm{p}$ labeled nucleoside triphosphate was added to a standard splicing reaction (with unlabeled transcript in place of ${ }^{32} \mathrm{P}$-labeled transcript) at the outset. Time points were taken at 1, 10, and 20 $\mathrm{min}$. At $10 \mathrm{~min}, 2 \mathrm{~mm}$ glucose was added to an aliquot of each splicing reaction, and the NTP in each was monitored at 13 and $18 \mathrm{~min}$ ( 3 and $8 \mathrm{~min}$ after the addition of glucose). The TLC was run in $1.2 \mathrm{M} \mathrm{LiCl}$. The positions of each NTP (or dATP) and NDP (or dADP) are indicated. 
sured using bioluminescence; for this measurement, NTPs in a phenol-extracted extract were converted to ATP using nucleoside diphosphate kinase. The concentration of NTPs other than ATP was $\sim 1 \mu \mathrm{M}$. The depletion of the NTPs may result from their rapid conversion to ATP. We found that $2 \mathrm{~mm}$ glucose was sufficient for the depletion of ATP; 2 mM ATP added after the depletion was relatively stable. When $5 \mathrm{~mm}$ glucose was used for the depletion, additional ATP was not stable.

Using this method for removing ATP, we carried out chase experiments analogous to those described above. An outline of the experiment is shown above the gel in Figure 4A. Splicing was carried out under normal conditions in a PRP18-depleted extract. At $t=10 \mathrm{~min}$ (or $t=9 \mathrm{~min}$ ) a portion of this splicing reaction was transferred to a tube containing sufficient glucose to bring the final concentration of glucose to $2 \mathrm{mM}$ (or $5 \mathrm{mM}$ ). After a 4-min incubation to allow depletion of the ATP, either PRP18 or PRP18 and ATP were added. A gel showing the time course of each of the different reactions is pictured in Figure 4A; a single splicing reaction was the starting point for all of the samples shown in Figure 4. The main conclusion from this experiment is that ATP is not required for chasing of the intermediates to products by PRP18. This conclusion can be seen from a comparison of the amounts of the spliced RNAs in the ATP-depleted splicing reaction before the addition of PRP18 (lane F) and 3 min after the addition of PRP18 (lane I). In the absence of ATP, the addition of PRP18 caused a reduction in the amounts of $2 / 3$ lariat and exon 1 intermediates, and an increase in the amounts of $\mathrm{mRNA}$ and lariat intron. There was a twofold increase in the amount of mRNA, and a threefold increase in the amount of intron. About $35 \%$ of the $2 / 3$ lariat consumed in the reaction is found in mRNA. When ATP was added with PRP18, the chase was apparently more complete, and the apparent yield of mRNA was higher $(55 \%)$.

Figure 4, B and C, shows graphically the amounts of
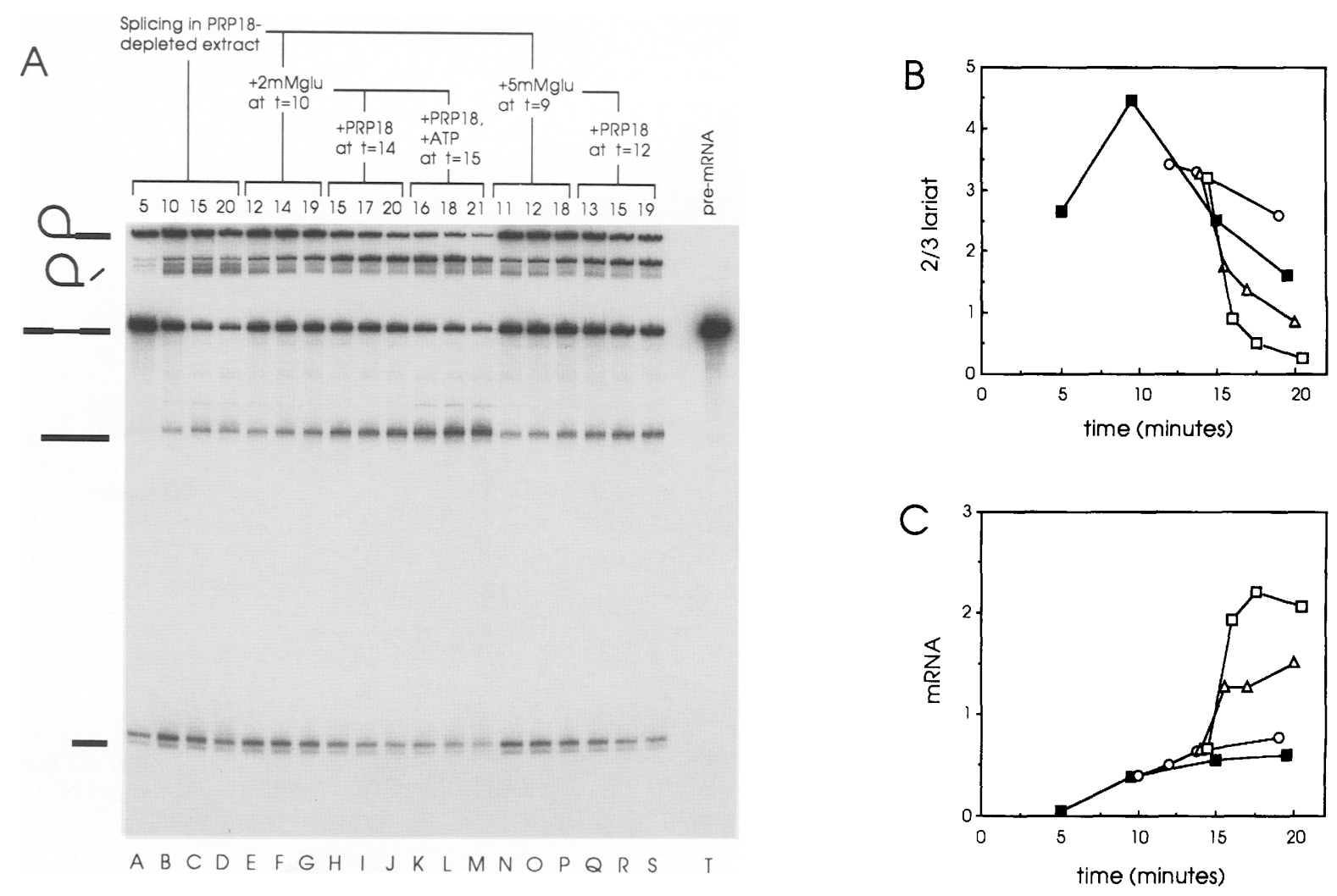

Figure 4. Chasing of intermediates to products by PRP18 in the absence of ATP. (A) A flowchart of the experiment is shown above the gel. A single splicing reaction using a PRP18-depleted extract was the parent reaction for all of the lanes shown. Lanes $A-D$ show the kinetics of splicing in this reaction. At 10 (or 9) $\mathrm{min}$, glucose was added to an aliquot of the splicing reaction to give a final concentration of $2 \mathrm{mM}$ (or $5 \mathrm{mM}$ ). The time course of splicing after the addition of glucose was followed (lanes $E-G$, and lanes $N-P$ ). PRP18 (lanes $H-I$, and lanes Q-S) or PRP18 and ATP (lanes $K-M$ ) were added 3-4 min after the addition of glucose and splicing followed. The positions of the various RNA species are indicated as in Fig. 2A. All times have been rounded to the nearest minute. (B) Quantitation of the chasing of $2 / 3$ lariat. The amounts of $2 / 3$ lariat in the PRP18-depleted extract (from lanes $A-D ;$ plus $2 \mathrm{~mm}$ glucose (from lanes $E-G$; O), chased with PRP18 (from lanes $H-$ ); $\triangle$ ), and chased with PRP18 and ATP (from lanes $K-M$; $\square)$ are shown. $(C)$ Quantitation of the formation of mRNA in the chasing experiment. The same samples and symbols are plotted here as in $B$. The $2 / 3$ lariat and mRNA axes in $B$ and $C$ are in the same (relative molar) units. For $B$ and $C$ the amount of $2 / 3$ lariat or mRNA at the start of each chase was interpolated from the 14- and 19-min time points (lanes $F, G$ ) the adjustment for the interpolation is small, and the conclusions drawn from the data do not depend on the precision of the interpolation. 
2/3 lariat and mRNA present in lanes $A-M$ in the gel shown in Figure 4A. The time course of splicing in the PRP18-depleted extract (lanes A-D) is essentially the same as that shown in Figure 2C. Following depletion of ATP, the pre-mRNA was stable (lanes E-G and N-P). In these ATP-depleted extracts, 2/3 lariat and exon 1 were not entirely stable (Fig. 4B), and a small amount of mRNA was produced (Fig. 4C). This observation is consistent with the idea that neither PRP18 nor ATP is required (although both are beneficial) for the second reaction. Addition of PRP18 (lanes H-J) or PRP18 and ATP resulted in a rapid decline in the amounts of $2 / 3$ lariat (Fig. 4B) and exon 1. (The decrease in the amount of exon 1 occurs at $\sim 65 \%$ of the rate of that of $2 / 3$ lariat in all of the chase experiments in Figs. 2 and 4.) mRNA (Fig. 4C) and intron are produced during the chase. The twofold increase in the amount of mRNA produced in the absence of ATP is reproducibly seen. Essentially identical chasing was seen when $5 \mathrm{~mm}$ glucose was used to deplete the ATP (Fig. 4A, lanes N-S); in this case, ATP added after the depletion is not stable because of the excess of glucose.

In the control experiments for the ATP-independent chasing experiment, we particularly wished to be able to determine whether ATP might be bound to the spliceosome before the second step of splicing occurs and then used during the reaction, and whether the concentration of ATP might still be high enough after the depletion of ATP to support splicing. We carried out an experiment identical to that in Figure 4 except that a preimmune antibody-depleted extract was used in place of the $\alpha$ PRP18-depleted extract (data not shown). After depletion of the ATP, the pre-mRNA, the splicing intermediates, and both products of the splicing reaction were stable, declining by $<15 \%$ during the $8 \mathrm{~min}$ incubation. Figure 2D shows that the levels of all of the RNAs except the pre-mRNA change only slowly in the interval from 10 to $20 \mathrm{~min}$ in the presence of ATP, so little can be attributed to their increased stability. However, there was no indication that $2 / 3$ lariat and exon 1 could be further spliced following the depletion of ATP, as might be expected if sufficient ATP remained to carry out the second step after depletion of ATP. We do not know why the pre-mRNA is stable in the absence of ATP; it may be protected against attack, because the debranched intron is rapidly degraded in the absence of ATP.

A second control experiment is shown in Figure 5 . Extract was incubated under splicing conditions in the absence of pre-mRNA. Glucose was added to deplete the ATP, and then either pre-mRNA or pre-mRNA and ATP were added, as outlined in Figure 5. No splicing of the added pre-mRNA was seen unless ATP was also added, showing that the remaining ATP was insufficient to support the complete splicing reaction.

\section{Discussion}

We have analyzed pre-mRNA splicing in yeast extracts depleted of the PRP18 protein. We showed that PRP18 is involved only in the second step of splicing. Intermedi-

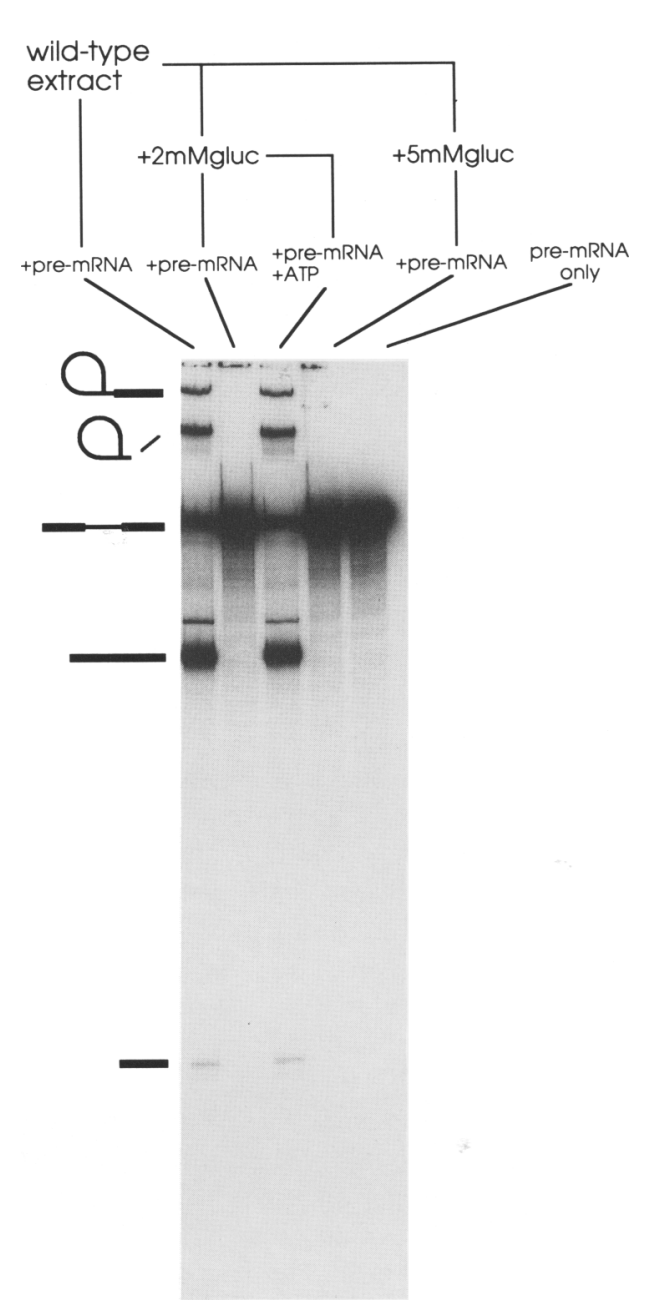

Figure 5. An assay of splicing in an ATP-depleted extract. A wild-type extract was incubated under splicing conditions without transcript for $10 \mathrm{~min}$; glucose was added as indicated; incubation was continued for $4 \mathrm{~min}$; transcript /with or without ATP/ was added; and splicing was assayed in a 15-min reaction. The positions of the RNAs are indicated symbolically, as in Fig. 2.

ates accumulated in splicing reactions in the absence of PRP18, and these intermediates could be rapidly chased to products by added PRP18 even in the absence of ATP.

We carried out an analysis of the kinetics of splicing in a PRP18-depleted extract. Depletion of PRP18 had no effect on the first step of splicing but did slow the second step substantially, showing that PRP18 is involved only in the second step of splicing. The second step was not, however, completely inhibited. While this remaining splicing activity may have been the result of a trace of PRP18 in the extract, we believe that this activity indicates that PRP18 is not absolutely required for the second step of splicing. As reported (D. Horowitz and J. Abelson in prep.), yeast strains bearing a null allele of PRP18 are viable at $23^{\circ} \mathrm{C}$, but grow extremely slowly, and do not grow at $37^{\circ} \mathrm{C}$; even at $23^{\circ} \mathrm{C}$ these yeast strains accumulate unspliced RNA. Corresponding results were 
obtained in vitro; in extracts depleted of PRP18, the rate of the second step of splicing declined as the temperature was increased. We concluded that PRP18 was not absolutely essential for splicing, and, hence that the residual splicing activity at $23^{\circ} \mathrm{C}$ in the PRP18-depleted extracts represents PRP18-independent splicing. As discussed in D. Horowitz and J. Abelson (in prep.), where we showed that PRP18 is associated with the U5 snRNP, the results of the kinetic analysis imply that the U5 snRNP is involved in the second step.

Wild-type splicing activity can be restored to PRP18depleted extracts by the addition of purified PRP18 protein. Analogous experiments with other PRP proteins have generally, but not always, been successful (Chang et al. 1988). The $2 / 3$ lariat and exon 1 intermediates that accumulate during splicing in a PRP18-depleted extract can be chased to products by the addition of purified PRP18 protein. This chase shows that the PRP18-binding site remains accessible in the spliceosome; similar experiments have been reported with PRP2 and PRP16 proteins (Lin et al. 1987; Schwer and Guthrie 1991). As described in Results, the chasing of the accumulated $2 / 3$ lariat and exon 1 to products is unambiguous and proves that they are intermediates in the splicing pathway.

The chasing of intermediates made in a PRP18-depleted extract to products was not dependent on ATP. Following the formation of intermediates in a PRP18depleted extract, the ATP was depleted by the addition of glucose. PRP18 was then added, leading to chasing of the $2 / 3$ lariat and exon 1 to mRNA and lariat intron (Fig. 4). This experiment strongly suggests that ATP hydrolysis is not coupled to the second cleavage-and-ligation reaction in pre-mRNA splicing. Depletion of ATP was followed by TLC and bioluminescence; we found that the ATP concentration had been reduced $\sim 700$-fold, from 2 mM to $\sim 3 \mu \mathrm{M}$. PRP2 and PRP16, which are both ATPases required for splicing, have been shown to hydrolyze NTPs other than ATP (Kim et al. 1992; Schwer and Guthrie 1992); we therefore measured the concentrations of other NTPs and found that all were substantially depleted when the ATP was depleted. Control experiments showed that the amount of ATP remaining was insufficient to support splicing. Experiments on PRP2, which is required for the first step of splicing, have shown that $20 \mu \mathrm{M}$ ATP is needed for good PRP2 activity (S.-H. Kim and R.-J. Lin, personal communication). For PRP16, which is required for the second step of splicing, $100 \mu \mathrm{M}$ ATP is sufficient for good splicing activity in chasing experiments (Schwer and Guthrie 1992). Our measured ATP concentration is significantly lower than that needed by PRP2 or PRP16, but comparisons of these numbers, derived from different procedures using different splicing extracts, are problematic. There is a possibility that ATP is stably bound to the spliceosome in our reaction before the depletion takes place and that this bound ATP is then hydrolyzed during the second reaction. Although this possibility is not addressed by our experiments, it would require that ATP have a high affinity for the spliceosome. A dissociation constant of 3 $\mu \mathrm{M}$ corresponds to a $7 \mathrm{kcal}$-binding energy /using
$\Delta \mathrm{G}=-\mathrm{RT} \log \mathrm{K}$ ), about half of the energy available from ATP hydrolysis. A more difficult question to answer is whether there is energy stored in the spliceosome. Energy could be stored as chemical energy, as in an adenylylated protein, or as mechanical energy. Our experiments do not address this question.

Following the depletion of ATP, the chasing of intermediates to products was apparently more efficient if ATP was included in the chase. This result is puzzling if the chase reaction is independent of ATP. One explanation for this observation is that in the absence of ATP there is no driving force for the reaction. We expect that in the second reaction the reactants and products are similar in free energy. Therefore, in the absence of ATP in the chase, the intermediates and products may be approaching equilibrium. The disassembly of the spliceosome is very likely an active process involving ATP hydrolysis by the PRP22 protein (Company et al. 1991). Thus, in the presence of ATP, the products are pushed forward in the splicing pathway by ATP hydrolysis, and the equilibrium in the second reaction of splicing is shifted far toward the formation of products. Similar energetic schemes apply to self-splicing RNAs, in which splicing is driven by cyclization of the intron after the splicing reaction is completed (Zaug et al. 1983). ATP might also lead to improvement in the chasing efficiency if some of the 2/3 lariat and exon 1 seen is present in complexes that are stopped at steps before, for example, the PRP16-requiring step, as might occur if PRP18 has some effect on the early stages of the second step. Two other factors also may complicate the comparison of chasing in the absence and presence of ATP. First, the stabilities of the various RNAs are different and are affected by ATP; and, second, in the presence of ATP, premRNA may be spliced to mRNA during the chase. Therefore, some of the difference in the efficiencies of chasing may be misleading.

Vijayraghavan and Abelson (1990) carried out a different type of chasing experiment using extracts from prp18 temperature-sensitive strains. In their experiments, spliceosomes formed in heat-inactivated extracts from a prp18 temperature-sensitive strain were purified in glycerol gradients. Chasing of the intermediates to products, done with heat-inactivated extracts from other prp temperature-sensitive strains, or with fractionated extracts, required ATP. Our results show that the second step of splicing continues in PRP18-depleted extracts lacking ATP; we suggest that during the sedimentation of spliceosomes, all of the PRP18-chasable intermediates were spliced, leaving only intermediates trapped at earlier stages of the second step. Chasing from these stages requires ATP (Schwer and Guthrie 1991).

The finding that the second cleavage-and-ligation reaction of splicing proceeds in the absence of ATP strongly supports the idea that this reaction is a transesterification (Cech 1986; Jacquier 1990). In the absence of ATP hydrolysis or other energy source, the number of phosphodiester bonds must be conserved during the reaction, as is the case in a transesterification. Both group I and group II self-splicing occurs by transesterification 
mechanisms, and the similarity between the intermediates and products in pre-mRNA splicing and group II splicing has led to suggestions that these two types of splicing are evolutionarily or mechanistically related (Cech 1986; Jacquier 1990). U6 snRNA has often been proposed as the RNA catalyst of the transesterification reaction, owing to its high degree of evolutionary conservation (Brow and Guthrie 1988), its involvement in both steps of splicing (Fabrizio and Abelson 1990), and its similarity to other self-splicing RNAs (Tani and Ohshima 1991). A recent proposal suggests that the second reaction of splicing is analogous to group I splicing, with the U2 and U6 snRNAs playing the leading catalytic roles (McPheeters and Abelson 1992). Although our data do support the idea that the splicing reaction is a transesterification, they do not address the question of what components of the spliceosome are directly involved in the second step.

ATP hydrolysis has been shown to be required for both steps of splicing (Krainer et al. 1984; Lin et al. 1985; Sawa et al. 1988; Vijayraghavan and Abelson 1990; Schwer and Guthrie 1991). Our finding implies that hydrolysis of ATP precedes the actual transesterification reaction, at least for the second step. In yeast, ATP hydrolysis by two proteins, PRP2 and PRP16, which both RNA-dependent ATPases, has been studied extensively, and the results of these studies are consistent with our conclusions. PRP16 is required for the second step of splicing, and we would expect it to act before the second reaction. Spliceosomes assembled without PRP16 carry out the first step of splicing; Schwer and Guthrie (1992) have recently shown that addition of PRP16 and ATP to these spliceosomes causes a conformational change in the spliceosome, which makes the 3' splice site inaccessible for oligonucleotide-directed cleavage by RNase $\mathrm{H}$. This conformational change, which requires hydrolysis of ATP, occurs in mutant substrates that do not undergo the second step of splicing, suggesting that the ATP hydrolysis carried out by PRP16 precedes the transesterification reaction. The PRP2 protein is required for the first step of splicing (Lin et al. 1987). Spliceosomes assembled without PRP2 require both PRP2 and ATP, but no other extrinsic factors, to carry out the first step of splicing (Kim and Lin 1993). However, no direct connection between ATP hydrolysis and the splicing reaction has been demonstrated.

Our results have a number of implications for the role of PRP18 in pre-mRNA splicing. As discussed above, PRP18 is involved exclusively in the second step of splicing; it is not absolutely required for splicing at low temperatures, although the second step is greatly slowed in the absence of PRP18. Several other factors are also involved in the second step of splicing, including three proteins, PRP16 (Schwer and Guthrie 1991), PRP17 (Vijayraghavan et al. 1989), and SLU7 (Frank et al. 1992) and three U snRNAs, U2 (McPheeters and Abelson 1992), U5 (Newman and Norman 1992; D. Horowitz and J. Abelson, in prep.), and U6 (Fabrizio and Abelson 1990). The ATP independence of the chasing of intermediates into products by PRP18 allows us to order the actions of some of these factors. It is clear that PRP18 acts after PRP16. The ATP dependences for the chasing of intermediates into products for other splicing factors have not yet been determined, so they cannot presently be ordered.

Our findings lead us to suggest that PRP18 functions during the second transesterification reaction, in contrast to PRP16 and SLU7, which appear to act before the actual cleavage-and-ligation reaction. This conclusion is suggested primarily by the absence of an ATP requirement for the chasing of intermediates to products by PRP18. This finding restricts the number and kinds of conformational changes that can occur between the addition of PRP18 and the second transesterification, precluding, for example, proofreading steps. We think that it is plausible that PRP18 acts during the transesterification reaction. The precise role of PRP18 in the reaction remains to be defined; it may play a largely structural role, stabilizing a conformation of the U5 snRNP, or it may be a more active participant.

\section{Materials and methods}

Materials and strains

Yeast splicing extracts (Lin et al. 1985) were made from CBO18 (a CRY1 pep $4 \Delta::$ HIS3 prb1::hisG prc1 $::$ hisG) (from J. Robinson, California Institute of Technology, Pasadena). Labeled nucleotides were from New England Nuclear. The luciferinluciferase ATP Assay Kit, nucleoside diphosphate kinase, and protein A-Sepharose were from Sigma. The Enhanced Chemiluminescence (ECL) system was from Amersham. $\alpha$ PRP18 antiserum is described by D. Horowitz and J. Abelson (in prep.); in this study we used the antibody referred to as $\alpha \mathrm{A}$.

\section{Depletion of PRP18 from yeast extracts}

Fifty microliters of protein A-Sepharose was incubated with $240 \mu \mathrm{l}$ of $\alpha$ PRP1 8 or preimmune serum for $1 \mathrm{hr}$ and then washed extensively. Yeast splicing extract $(300 \mu \mathrm{l})$ containing $20 \mathrm{~mm}$ $\mathrm{K}_{2} \mathrm{HPO}_{4} / \mathrm{KH}_{2} \mathrm{PO}_{4}$ at $\mathrm{pH} 7.4$ (20 mM phosphate), $100 \mathrm{~mm} \mathrm{KCl}$, and $0.05 \% \mathrm{NP}-40$ was added to the resin, incubated for $70 \mathrm{~min}$ at $4^{\circ} \mathrm{C}$, recovered by filtration, added to $15 \mu$ l of protein A-Sepharose, incubated for $30 \mathrm{~min}$ at $4^{\circ} \mathrm{C}$, and recovered by filtration.

\section{Western blotting}

Western blotting was carried out as described by D. Horowitz and J. Abelson (in prep.), using the ECL system.

\section{Splicing reactions}

Splicing was carried out as described in Lin et al. (1985). The total concentration of $\mathrm{K}_{2} \mathrm{HPO}_{4} / \mathrm{KH}_{2} \mathrm{PO}_{4}$ was $40 \mathrm{mM}$ (to account for the additional $\mathrm{KCl}$ present in the depleted extracts) when antibody-depleted extracts were assayed. To deplete ATP, glucose in a minimum volume was added to a final concentration of $2 \mathrm{mM}$ (or $5 \mathrm{mM}$ ). All incubations were carried out at $23^{\circ} \mathrm{C}$. For reconstitution of activity with PRP18, 15-30 ng of PRP18 per microliter of yeast extract was added; similar amounts of PRP18 were used in the chasing experiments. PRP18 was expressed in and purified to near homogeneity from Escherichia coli, as described by D. Horowitz and J. Abelson (in prep.). All gels were quantitated on a Molecular Dynamics PhosphorImager.

The rate constant for the second step of splicing was esti- 
mated as follows. We assumed that the second step could be modeled as a single-step, unimolecular reaction, and that degradation of mRNA could be neglected. The rate equation for the production of mRNA is $\mathrm{d}[\mathrm{mRNA}] / \mathrm{dt}=\mathrm{k}_{2}$ [exon $1 \cdot 2 / 3$ lariat], where exon $1 \cdot 2 / 3$ lariat represents the spliceosome containing the two intermediates. This equation was approximated as $\Delta[$ mRNA $] / \Delta t \sim \mathrm{k}_{2}[\text { exon } 1 \cdot 2 / 3 \text { lariat }]_{\text {avg }}$ for the time intervals shown in Figure 2, allowing us to calculate values for $k_{2}$.

\section{NTP assays}

Thin-layer chromatographs were run on polyethyleneiminecellulose with $1.2 \mathrm{M} \mathrm{LiCl}$, as described in Randerath and Randerath (1964). Luciferin-luciferase assays for ATP were carried out according to the manufacturer's recommendations. ATP was assayed directly in splicing reaction mixtures depleted of ATP with $2 \mathrm{~mm}$ or $5 \mathrm{~mm}$ glucose, yielding an ATP concentration of $2 \mu \mathrm{M}$; ATP was also assayed in phenol- and ether-extracted splicing reaction mixtures after ATP depletion, yielding a value of $3 \mu \mathrm{M}$. For measurement of the total NTP concentration, 20 $\mu \mathrm{M}$ ADP and nucleoside diphosphate kinase were added to phenol- and ether-extracted reaction mixtures to convert NTPs to ATP, whose concentration was measured. Where possible, internal standards were used to calibrate the measurements.

\section{Acknowledgments}

We are grateful to Han Htun, Adrian Krainer, R.-J. Lin, David McPheeters, Donald Morisato, and Christine O'Day for their helpful comments on the manuscript, and Dan Frank and Beate Schwer for communicating results before publication. D.S.H. was supported in part by the Damon Runyon-Walter Winchell Cancer Research Fund (DRG-924). This work was supported by the National Institutes of Health (GM32367).

The publication costs of this article were defrayed in part by payment of page charges. This article must therefore be hereby marked "advertisement" in accordance with 18 USC section 1734 solely to indicate this fact.

\section{References}

Banroques, J. and J.N. Abelson. 1989. PRP4: A protein of the yeast U4/U6 small nuclear ribonucleoprotein particle. Mol. Cell. Biol. 9: 3710-3719.

Black, D.L. and A.L. Pinto. 1989. U5 small nuclear ribonucleoprotein: RNA structure analysis and ATP-dependent interaction with U4/U6. Mol. Cell. Biol. 9: 3350-3359.

Brow, D.A. and C. Guthrie. 1988. Spliceosomal RNA U6 is remarkably conserved from yeast to mammals. Nature 334: 213-218.

Burgess, S., J.R. Couto, and C. Guthrie. 1990. A putative ATP binding protein influences the fidelity of branchpoint recognition in yeast splicing. Cell 60: 705-717.

Cech, T.R. 1986. The generality of self-splicing RNA: Relationship to nuclear mRNA splicing. Cell 44: 207-210.

Chang, T.-H., M.W. Clark, A.J. Lustig, M.E. Cusick, and J. Abelson. 1988. RNAl1 protein is associated with the yeast spliceosome and is localized in the periphery of the cell nucleus. Mol. Cell. Biol. 8: 2379-2393.

Company, M., J. Arenas, and J. Abelson. 1991. Requirement of the RNA helicase-like protein PRP22 for release of messenger RNA from spliceosomes. Nature 349: 487-493.

Couto, J.R., J. Tamm, R. Parker, and C. Guthrie. 1987. A transacting suppressor restores splicing of a yeast intron with a branch point mutation. Genes \& Dev. 1: 445-455.
Fabrizio, P. and J. Abelson. 1990. Two domains of yeast U6 small nuclear RNA required for both steps of nuclear precursor messenger RNA splicing. Science 250: 404-409.

Frank, D. and C. Guthrie. 1992. An essential splicing factor, SLU7, mediates 3' splice site choice in yeast. Genes \& Dev. 6: 2112-2124.

Frank, D., B. Patterson, and C. Guthrie. 1992. Synthetic lethal mutations identify interactions between U5 snRNA and four proteins required for the second step of splicing. Mol. Cell. Biol. 12: 5197-5205.

Green, M.R. 1991. Biochemical mechanisms of constitutive and regulated pre-mRNA splicing. Annu. Rev. Cell Biol. 7: 559599.

Guthrie, C. 1991. Messenger RNA splicing in yeast: Clues to why the spliceosome is a ribonucleoprotein. Science 253: 157-163.

Jacquier, A. 1990. Self-splicing group II and nuclear pre-mRNA introns: How similar are they? Trends Biochem. Sci. 15: 351-354.

Jackson, S.P., M. Lossky, and J.D. Beggs. 1988. Cloning of the RNA8 gene of Saccharomyces cerevisiae, detection of the RNA8 protein, and demonstration that it is essential for nuclear pre-mRNA splicing. Mol. Cell. Biol. 8: 1067-1075.

Kim, S.-H. and R.-J. Lin. 1993. Pre-mRNA splicing within an assembled yeast spiceosome requires an RNA-dependent ATPase and ATP hydrolysis. Proc. Natl. Acad. Sci. (in press).

Kim, S.-H., J. Smith, A. Claude, and R.-J. Lin. 1992. The purified yeast pre-mRNA splicing factor PRP2 is an RNA-dependent NTPase. EMBO J. 11: 2319-2326.

Krainer, A.R., T. Maniatis, B. Ruskin, and M. R. Green. 1984. Normal and mutant human $\beta$-globin pre-mRNAs are faithfully and efficiently spliced in vitro. Cell 36: 993-1005.

Lin, R.-J., A.J. Newman, S.-C. Cheng, and J. Abelson. 1985. Yeast mRNA splicing in vitro. J. Biol. Chem. 260: 1478014792.

Lin, R.-J., A.J. Lustig, and J. Abelson. 1987. Splicing of yeast nuclear pre-mRNA in vitro requires a functional $40 \mathrm{~S}$ spliceosome and several extrinsic factors. Genes \& Dev. 1: 7-18.

McPheeters, D.S. and J. Abelson. 1992. Mutational analysis of the yeast U2 snRNA suggests a structural similarity to the catalytic core of group I introns. Cell 71: 819-831.

Newman, A.J. and C. Norman. 1992. U5 snRNA interacts with exon sequences at $5^{\prime}$ and $3^{\prime}$ splice sites. Cell 68: 743-754.

Peebles, C.L., P.S. Perlman, K.L. Mecklenburg, M.L. Petrillo, J.H. Tabor, K.A. Jarrell, and H.-L. Cheng. 1986. A self-splicing RNA excises an intron lariat. Cell 44: 213-223.

Petersen-Bjøm, S., A. Soltyk, J.D. Beggs, and J.D. Friesen. 1989. PRP4 (RNA4) from Saccharomyces cerevisiae: Its gene product is associated with the U4/U6 small nuclear ribonucleoprotein particle. Mol. Cell. Biol. 9: 3698-3709.

Randerath, K. and E. Randerath. 1964. Ion-exchange chromatography of nucleotides on poly-(ethyleneimine)-cellulose thin layers. J. Chromatog. 16: 111-125.

Reich, C.I., R.W. VanHoy, G.L. Porter, and J.A. Wise. 1992. Mutations at the $3^{\prime}$ splice site can be suppressed by compensatory base changes in U1 snRNA in fission yeast. Cell 69: 1159-1169.

Ruby, S.W. and J. Abelson. 1991. Pre-mRNA splicing in yeast. Trends Genet. 7: 79-85.

Sawa, H., M. Ohno, H. Sakamoto, and Y. Shimura. 1988. Requirement for ATP in the second step of the pre-mRNA splicing reaction. Nucleic Acids Res. 16: 3157-3164.

Schwer, B. and C. Guthrie. 1991. PRP16 is an RNA-dependent ATPase that interacts transiently with the spliceosome. $\mathrm{Na}$ ture 349: 494-499.

- 1992. Conformational rearrangement in the spliceo- 
some is dependent on PRP16 and ATP hydrolysis. EMBO J. 11: 5033-5039.

Tani, T. and Y. Ohshima. 1991. mRNA-type introns in U6 small nuclear RNA genes: Implications for the catalysis in premRNA splicing. Genes \& Dev. 5: 1022-1031.

van der Veen, R., A.C. Arnberg, G. van der Horst, L. Bonen, H.F. Tabak, and L.A. Grivell. 1986. Excised group II introns in yeast mitochondria are lariats and can be formed by selfsplicing in vitro. Cell 44: 225-234.

Vijayraghavan, U. and J. Abelson. 1990. PRP18, a protein required for the second reaction in pre-mRNA splicing. Mol. Cell. Biol. 10: 324-332.

Vijayraghavan, U., M. Company, and J. Abelson. 1989. Isolation and characterization of pre-mRNA splicing mutants of Saccharomyces cerevisiae. Genes \& Dev. 3: 1206-1216.

Zaug, A.J., P.J. Grabowski, and T.R. Cech. 1983. Autocatalytic cyclization of an excised intervening sequence RNA is a cleavage-ligation reaction. Nature 301: 578-583. 


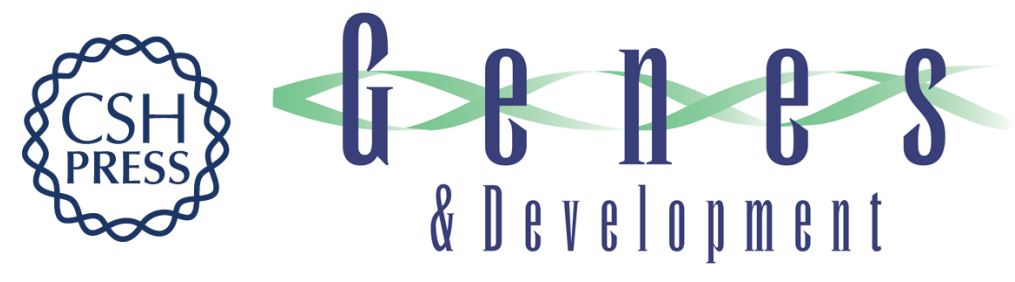

\section{Stages in the second reaction of pre-mRNA splicing: the final step is ATP independent.}

D S Horowitz and J Abelson

Genes Dev. 1993, 7:

Access the most recent version at doi:10.1101/gad.7.2.320

References This article cites 34 articles, 14 of which can be accessed free at:

http://genesdev.cshlp.org/content/7/2/320.full.html\#ref-list-1

License

Email Alerting

Service top right corner of the article or click here.

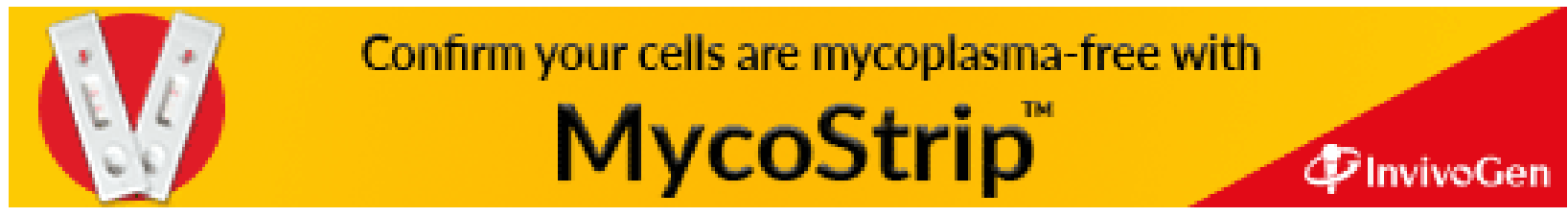

